\title{
$\mathrm{PH} 99_{\text {cosate }}$
}

a debate Patrocinio, mecenazgo, crowdfunding ¿compromiso social o marketing interesado?

| coordina Ana Isabel Velasco Rebollo

\section{Sostenibilidad y viabilidad para el patrimonio cultural ¿cómo hacerla posible?}

Ana Isabel Velasco Rebollo | Asociación Española de Gestores de Patrimonio Cultural (AEGPC)

URL de la contribución <www.iaph.es/revistaph/index.php/revistaph/article/view/4589>

Tras la reducción de la inversión pública en patrimonio cultural, motivada principalmente por la crisis económica, se ha hecho necesario revisar e incrementar las diferentes vías de financiación que permitan la restauración, conservación y puesta en valor de un patrimonio de un valor incuestionable material e inmaterial y que, sin duda, constituye uno de los principales alicientes para el turismo cultural, entre otras cosas, siendo una fuente de generación de desarrollo sostenible y transformación social.

No se trata solo de mantener o conservar, se trata de conseguir un plan de sostenibilidad y viabilidad a largo plazo para nuestro patrimonio cultural. Así un modelo mixto de financiación parece ser la solución a este problema, pero ¿cómo es posible conseguir esto?

En el momento de mayor esplendor, en los años 2007 y 2008, en todas las comunidades autónomas, las cajas de ahorro llegaron a invertir y destinar a la obra social y cultural una media del 25\% del beneficio de la caja. Fruto de esta inversión se llevaron a cabo proyectos de conservación y difusión del patrimonio, aportando presupuesto allí donde las instituciones públicas no llegaban y generando impacto social y económico, aunque este mecenazgo, en ocasiones, se utilizara a modo de complemento publicitario, como "carta de presentación", de su propia red comercial.

Tras la desaparición de las cajas de ahorro y su fusión con los bancos comerciales, las obras sociales se convirtieron, en la mayoría de los casos, en fundaciones bancarias que, aunque siguen comprometidos con la cultura y el patrimonio, no logra alcanzar las cifras de inversión anteriormente mencionadas.

Buen ejemplo de esto es la Fundación Caja Madrid, actualmente Fundación Montemadrid, que desde 1991

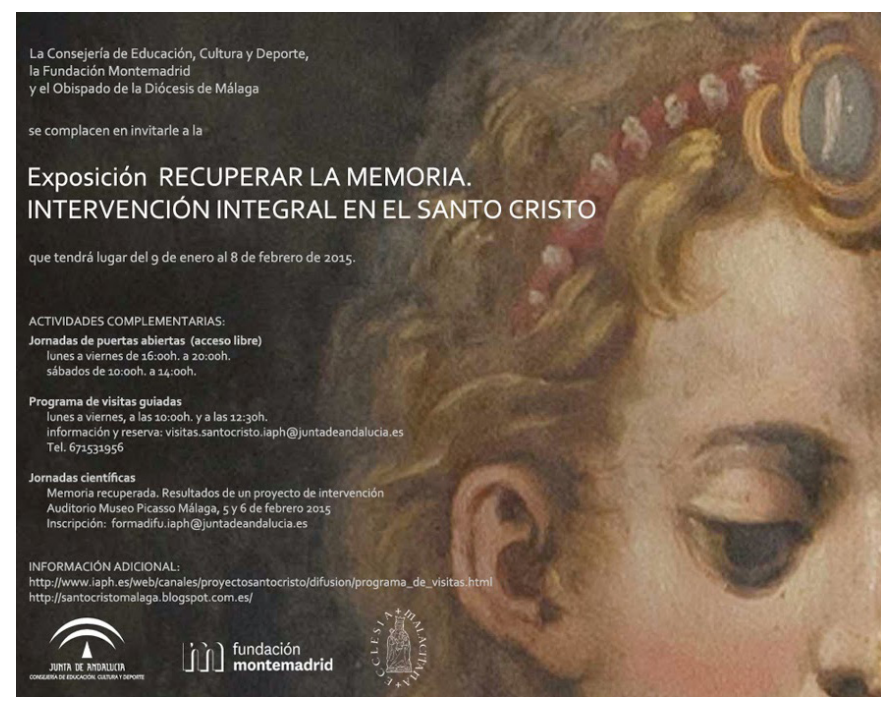

orientó una parte principal de su actividad y recursos a la conservación del patrimonio histórico mediante la creación de un programa específico, siendo la institución privada sin ánimo de lucro que más atención dedica al patrimonio histórico en España. "Esta fundación elabora, como parte del proyecto de restauración, un plan de comunicación y difusión adaptado a las características de cada monumento, en cuyo marco se organizan numerosas actividades de dinamización social del entorno en donde se ubica. Esto ha fomentado la generación de proyectos culturales de restauración de gran repercusión social y de gran capacidad para lograr un mayor retorno en imagen, en cantidad y en calidad de la responsabilidad social de la fundación" (MORATE MARTÍN, 2010).

En la actualidad, la financiación desde fondos públicos en la conservación, preservación, restauración y puesta en valor de nuestro patrimonio cultural es insuficiente, por lo que se ha hecho necesario buscar nuevas fuentes 
de financiación, utilizando diferentes vías para implicar a particulares, empresas y entidades privadas para contribuir a estos fines.

Los cambios en los procesos de comunicación de las empresas con sus públicos (el cliente tiene el poder sobre la reputación) hace que las marcas comerciales estén valorando nuevos medios para posicionarse y lograr la simpatía de los clientes. Un activo que está dando grandes resultados es asociar la marca con las inquietudes de la sociedad, transmitiendo su compromiso con la comunidad y su responsabilidad empresarial a través de la participación en el mantenimiento y conservación del patrimonio cultural.

La Responsabilidad Social Corporativa (RSC) es, según el Libro Verde de la Unión Europea, "La integración voluntaria, por parte de las empresas, de las preocupaciones sociales y medioambientales en sus operaciones comerciales y sus relaciones con sus interlocutores" (LIBRO, 2001).

Una buena manera de demostrar su implicación con la sociedad es unir la marca a la cultura, asociándola con los atributos de ésta. Para el patrimonio cultural, este enfoque puede ser muy útil en la captación de recursos, proponiendo a las marcas comerciales acciones de mecenazgo o de patrocinio total o parcial.
A eso podemos sumarle el hecho de que las acciones de comunicación que realizan las entidades patrocinadoras consiguen un mejor conocimiento del patrimonio en el que éstas invierten, incrementando el interés y la valoración del mismo por parte de la sociedad, convirtiéndose así en la mejor garantía de su conservación futura. Se conserva y se protege lo que realmente se conoce y se valora.

Uno de los principales elementos a tener en cuenta en el análisis del mecenazgo cultural en cualquier país es el nivel de compromiso emocional que la ciudadanía siente hacia el fomento de las artes, la cultural y el patrimonio. Son los individuos, no solo las empresas, los que gracias a este compromiso y con un comportamiento responsable se implican en la protección de su patrimonio y es en este contexto en el que surge el crowdfunding, financiación colectiva o microfinanciación que ha hecho posible restaurar, conservar y poner en valor un importante legado histórico artístico y cultural que se estaba perdiendo en grandes y pequeños municipios.

En este sentido hemos visto cómo se ha producido un incremento de la inversión por parte de las entidades privadas e incluso grandes corporaciones en la restauración y rehabilitación de patrimonio de reconocido prestigio, capaz de atraer un gran número de visitantes, dejando en un segundo plano la protección de ese patri-

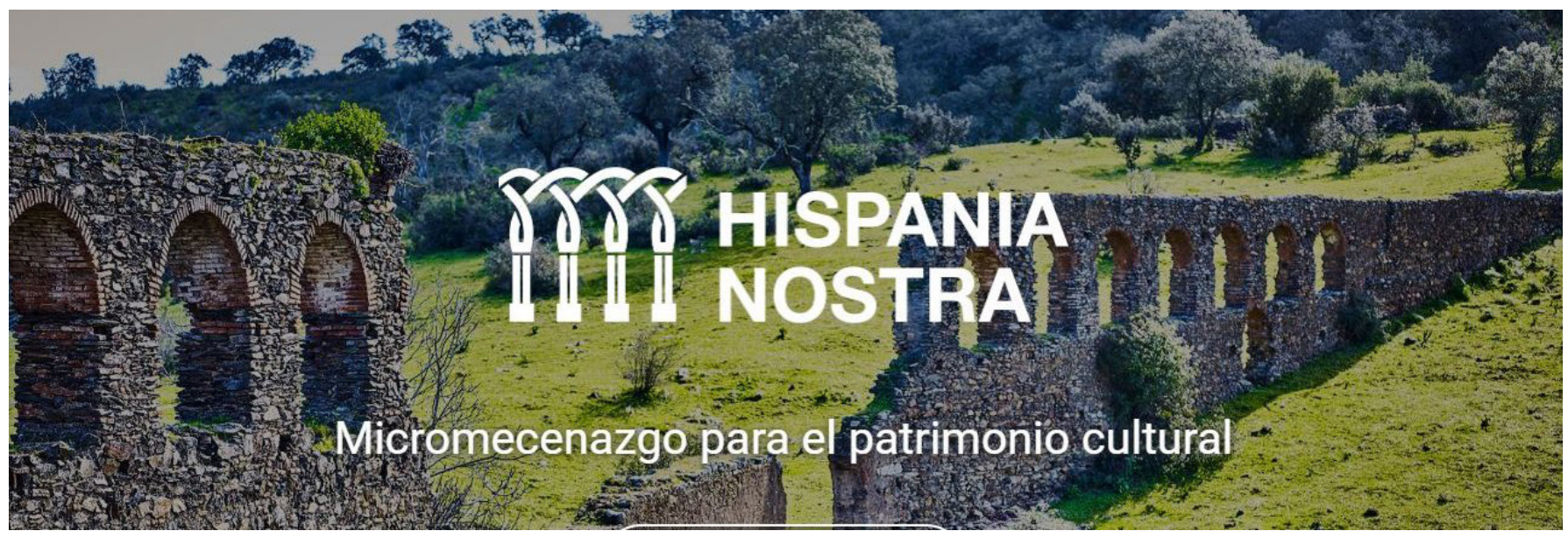


a debate Patrocinio, mecenazgo, crowdfunding ¿compromiso social o marketing interesado?

| coordina Ana Isabel Velasco Rebollo

monio que no tiene tanta visibilidad y es en este en el que las entidades locales y agrupaciones de ciudadanos incentivan la captación de recursos, recurriendo en la mayoría de las ocasiones a la búsqueda de recursos a través de la aportación colectiva o micromecenazgo.

Gracias al poder de las redes sociales e Internet, en los últimos años, han surgido diferentes plataformas de crowdfunding o financiación colectiva que proporcionan medios para recaudar fondos y lograr llevar a cabo diferentes proyectos, siendo la plataforma de micromecenazgo de Hispania Nostra la única especializada en patrimonio y cultura. Como esta entidad indica claramente en su web", "contar con el apoyo de una entidad de referencia en el ámbito del Patrimonio Cultural y Natural, aumenta el éxito de las campañas" y varios proyectos de restauración y recuperación de patrimonio han conseguido cumplir su objetivo gracias a las aportaciones económicas conseguidas a través de esta plataforma en la que personas u organizaciones se han implicado directamente obteniendo una desgravación fiscal de hasta el $75 \%$ de la donación.

Otro buen ejemplo de esto es la campaña "Súmate al Prado" de captación de recursos a través del crowdfunding realizada por el Museo del Prado para la compra del Retrato de niña con paloma del pintor francés del siglo XVII Simon Vouet, gracias a la cual el museo recaudó $204.713,1 €$ procedentes de la colaboración de 6.456 donantes $^{2}$. El éxito de estas campañas ha animado a otras entidades e instituciones a recaudar fondos por esta misma vía para el patrimonio que gestionan.

Debemos recordar, que tal y como establece la Ley, en los primeros $150 €$ de donación, la desgravación es del $75 \%$, es decir, 112,5 €. En cantidades superiores a $150 €$, la desgravación es del 75\% para los primeros 150€ y del $30 \%$ para el importe restante (35\% si llevas, al menos, 3 años consecutivos donando a la misma ONG).

La Ley 49/2002, de 23 de diciembre, de régimen fiscal de las entidades sin fines lucrativos y de los incentivos fiscales al mecenazgo, fue un hito en su momento al

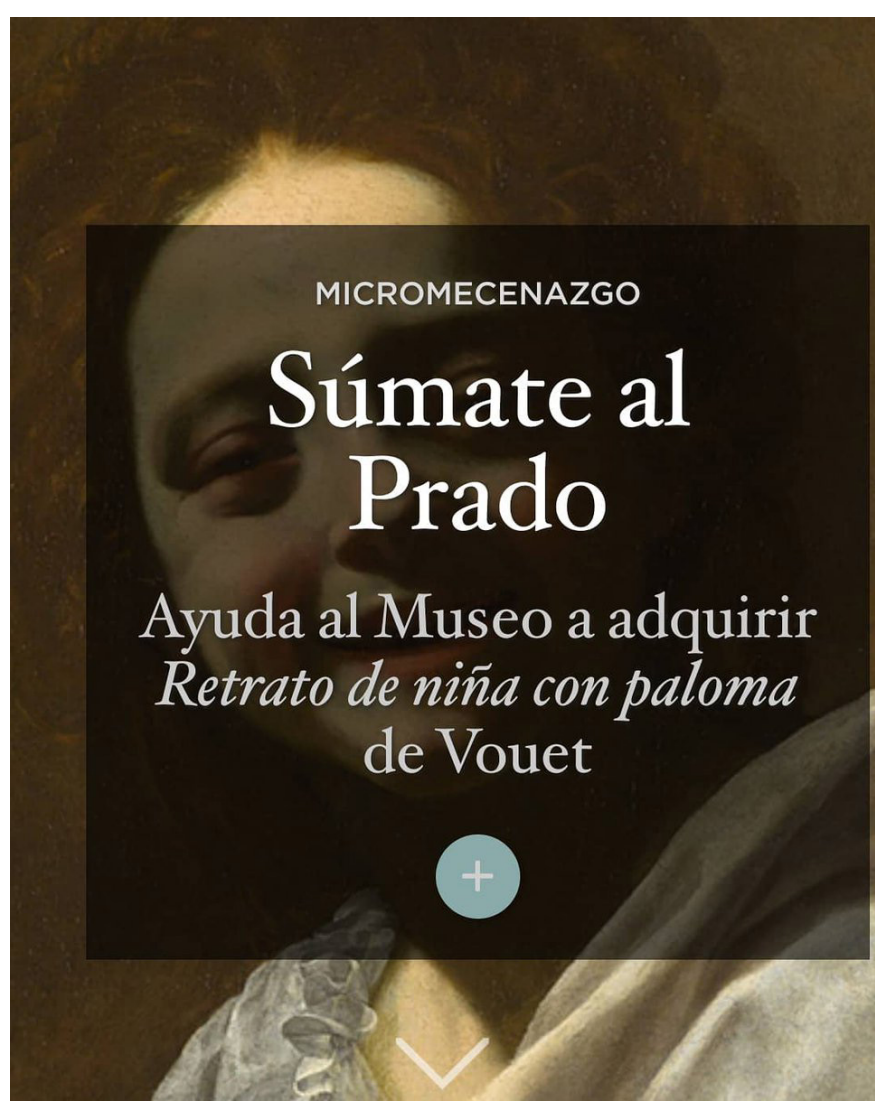

reconocer el Estado a través de la misma el papel fundamental de la sociedad civil en el apoyo a causas de interés general (ver Borja Álvarez, Eugenia Merino y Paz Martín en este mismo número, pp. 164-166). En esta ley los mayores incentivos son para donaciones a fundaciones o asociaciones declaradas de utilidad pública, lo que en ambos casos implica contar con objetivos y planes de acción bien definidos y cierta infraestructura de funcionamiento para atender tanto a la misión patrimonial como a la gestión administrativa y legal.

Dejando al margen que sean los bienes o instituciones más conocidos los objetos preferentes de atención, las pequeñas asociaciones, no declaradas de utilidad pública, no pueden ofrecer iguales beneficios fiscales (las aportaciones a estas deducen un 10\%) resultando así menos atractivas a la donación. 
En cualquier caso, estos incentivos fiscales no parecen ser suficientes para animar a la sociedad civil española a participar activamente en la salvaguarda y puesta en valor del patrimonio cultural. Según los datos del Special Eurobarometer 466. Cultural Heritage. Report de la Comisión Europea, en 2017, España está situada por debajo de la media europea tanto en la donación de recursos a entidades del ámbito del patrimonio, como en el trabajo voluntario en estas organizaciones (un $7 \%$ y un $5 \%$ respectivamente) y lejos de países como Holanda o Suecia, en los que el 19\% y $14 \%$ respectivamente de la ciudadanía realiza donaciones al sector patrimonial, siendo la empresa privada la excepción a esta situación (como comenta en este mismo debate Anna Villarroya, ver pp. 171-172). Si miramos hacia el ámbito anglosajón, prácticamente el $80 \%$ de las aportaciones a la cultura procede de los ciudadanos.

Ante estos datos deberíamos volver a preguntarnos por qué la ciudadanía no se implica en el mantenimiento y conservación de "su" patrimonio cultural, por qué no invierte en este y lo protege. Quizás la clave está en que parece que la mayoría no lo considera suyo, falta ese vínculo social que permite sentirlo y apreciarlo como propio. Por tanto, lo primero que se debería hacer es educar y promover políticas de concienciación, protección y conservación acertadas y efectivas, dándole sentido al patrimonio construido y vivido (patrimonio tangible e intangible) con un valor social y económico indiscutible, solo de esta manera será posible conseguir la implicación de la ciudadanía en la protección del bien a conservar que, si bien es parte de nuestro pasado, es nuestra mejor herencia, también lo es de nuestro presente y deberá ser parte del futuro.

\section{BIBLIOGRAFÍA}

- BALADO GARCíA, C. (2006) La obra social de las cajas, un paso siempre por delante. RSC, Papeles de Economía Española, n. ${ }^{\circ}$ 108, 2006, pp. 144-160

- GREFFE, X. (2015) El valor económico del patrimonio. En CATALÁN ROMERO, S. (coord.); GONZÁLEZ RUEDA, A. J. (ed.) Manual Atalaya. Apoyo a la gestión cultural [en línea] sl: Observatorio Cultural del Proyecto Atalaya, $2015<\mathrm{http}: / /$ atalayagestioncultural.es/pdf/09.3.pdf> [Consulta: 24/01/2020]

- LIBRO Verde fomentar un marco europeo para la Responsabilidad Social de las Empresas (2001) [en línea]. Bruselas: Comisión de las Comunidades Europeas, 18 de julio de 2001 (COM/2001/0366 final) <http://www.europarl.europa. eu/meetdocs/committees/deve/20020122/com(2001)366_ es.pdf> [Consulta: 27/01/2020]

- MORATE MARTíN, G. (2010) Aportaciones de la sociedad civil: El programa de conservación del patrimonio histórico español de la Fundación Caja Madrid. En HENARES CUÉLLAR, I. L. (coord.) La protección del patrimonio histórico en la España democrática. Granada: Universidad, 2010, pp. 297-318

- RAUSELL KÖSTER, P.; MONTAGUT MARQUÉS, J.; MINYANA BELTRÁN, T. (2013) Hacia nuevos modelos de financiación cultural. ¿Renovar el mecenazgo? Periférica: Revista para el análisis de la cultura y el territorio, n. ${ }^{\circ} 14,2013$, pp. 209-233

- RUBiO AROSTEGUI, J. A.; VILLAROYA PLANAS, A. (2019) El papel del mecenazgo en la política española. Propuestas para reconfgurar su papel en la crisis en las artes y la industria cultural [en línea]. Madrid: Ministerio de Cultura y Deporte (trabajo realizado por Fundación Alternativas para Unidad Cultura y Mecenazgo), 2019 <http://www.culturaydeporte. gob.es/dam/jcr:-fc0e64ed-7450-4878-a854-0e39e52bfc75/ papeldelmecenazgo.pdf> [Consulta: 09/01/2020]

\section{NOTAS}

\section{1. https://crowdfunding.hispanianostra.org}

\section{2. https://www.museodelprado.es/bicentenario/micro-} mecenazgo 